\title{
IMPLEMENTATION OF BIM AND LEAN CONSTRUCTION IN OFFSITE HOUSING CONSTRUCTION: EVIDENCE FROM THE UK
}

\author{
José A. Marte Gómez ${ }^{1}$, Emmanuel I. Daniel ${ }^{2}$, Yanqing Fang ${ }^{3}$, David Oloke ${ }^{4}$ and \\ Louis $\mathbf{G y o h}^{5}$
}

\begin{abstract}
The benefits of integrating Lean construction (LC) and Building Information Modelling (BIM) have been discussed in recent research studies. However, the effects of implementing these methodologies as an integrated approach in offsite housing construction (OSHC) processes have not been explored in the UK. This research aims at assessing the current situation of the implementation of BIM and LC in OSHC in the UK. A quantitative research method was adopted in the study and thirty-two questionnaire survey responses were received from professionals and practitioners of Lean, BIM and offsite methodologies in the UK construction industry. The study found that there is increasing use of LC and BIM in the development of OSHC projects in the UK. It further reveals that these two methodologies when appropriately implemented can bring several benefits. This study sheds light on the current status of implementation of BIM and LC in OSHC and the benefits of the implementation of both BIM and LC in OSHC processes in the UK.
\end{abstract}

\section{KEYWORDS}

Lean construction, building information modelling, offsite construction.

\section{INTRODUCTION}

The UK construction industry has expressed a growing interest in the improvement of essential areas of construction such as efficiency and production. Several aspects of performance enhancement approaches including offsite production, standardisation and supply chain partnerships have been addressed in reports such as the Offsite manufacture for construction report (UK parliament, 2018), the Farmer Review of the UK construction labour model (Farmer, 2016) and the Egan report (Egan, 1998). Nevertheless, the

MSc Graduate, School of Arch. and Built Envir., Faculty of Sci. and Engrg., Univ. of Wolverhampton, Wolverhampton, UK, jamartegomez@gmail.com, orcid.org/0000-0002-3311-4851

2 Sr. Lecturer in Constr. Mgmt., School of Arch. and Built Envir., Faculty of Sci. and Engrg., Univ. of Wolverhampton, Wolverhampton, UK, E.Daniel2@wlv.ac.uk, orcid.org/0000-0002-5675-1845

3 PhD Graduate, School of Management Science and Engineering, Tianjin University of Finance and Economics, China. fangyq_lc@ sina.com, orcid.org/0000-0003-2989-9737

4 Sr. Lecturer, School of Arch. and Built Envir., Faculty of Sci. and Engrg., Univ. of Wolverhampton, Wolverhampton, UK, D.A.Oloke@wlv.ac.uk, orcid.org/0000-0002-0730-7262

5 Principal Lecturer, School of Arch. and Built Envir., Faculty of Sci. and Engrg., Univ. of Wolverhampton, Wolverhampton, UK, L.Gyoh@wlv.ac.uk, orcid.org/0000-0002-8257-9380 
implementation of these performance improvement approaches has been hindered mostly due to complications that builders have encountered in appreciating the value these approaches may bring into their projects (Pasquire et al, 2004).

BIM is defined as a process for the creation and management of information of infrastructure, building or facility through its lifecycle (Eastman et al., 2008). This process results in the creation of the BIM, a digital representation of all the significant aspects of the building. BIM diverges from other design technologies in the way information is managed allowing an effective interchange of essential data between stakeholders throughout the project lifecycle and post-construction performance (Smith and Tardif, 2009). Lean construction (LC) is another performance enhancement approach that aims to improve the entire construction process in order to effectively satisfy the customer's needs (Bhatla and Leite 2012). LC focuses on reducing waste and increasing value which translates into quality and productivity improvement (Bernstein and Jones, 2013). The LC methodologies considered in this study include: Just-in-time, Visual management, Last Planner System, Target Value Design, Value Stream Mapping, 5S, Lean Project Delivery System, Process mapping, First run study, Mistake proofing, Takt time planning and Choosing by advantages.

LC and BIM have influenced considerably the AEC industry and despite being considered as distinct and independent, their principles seem to amalgamate in their intentions and ideals (Sacks et al., 2009). The synergies of BIM and LC have led the broadly fractured construction industry into a pathway of enhancing construction processes whilst increasing the value of a project towards the customer (Oskouie et al., 2012). Although the benefits of integrating BIM and LC have been discussed in recent studies (Sacks et al., 2009), the effects of integrating BIM and LC in offsite housing construction (OSHC) have not been explored in the UK.

This study aims to evaluate the current situation of the implementation of BIM and LC in OSHC. By identifying the actual status of the implementation of these methodologies, the results of this study would enable critical improvements on the benefits these methodologies bring into the UK construction industry. The research questions are as follows: What is the current status of implementation of BIM and LC in OSHC in the UK? What are the benefits of the implementation of the integrated BIM and $\mathrm{LC}$ in OSHC processes in the UK?

\section{LITERATURE REVIEW}

\section{LeAN CONSTRuCTION ANd OfFSITE CONSTRuCtion}

Offsite construction (OSC) involves the process of manufacturing components, elements or modules in a controlled environment before their transportation and later installation in the construction site (Kolo et al., 2014). This allows the achievement of higher standards of quality, waste reduction, and increased productivity, therefore improving the overall efficiency of the process (Nanyam et al., 2017). Pan and Goodier (2012) state that OSC represents an effective alternative to traditional construction processes by improving life cycle environmental performance, productivity and predictability.

Abanda et al. (2017) identify the main types of offsite manufacturing as Volumetric, 3D factory-produced units that enclose usable space but are not part of the building structure; Sub-assembly systems, prefabricated sections of the building that would normally be produced on site; Modular systems, volumetric units preassembled in a factory controlled environment and together form the whole building; Panelised, factory- 
produced flat panel units assembled on site to produce the 3D structure; and Hybrid methods, a combination of both volumetric and panelised systems.

OSC has been promoted in recent literature with the objective of improving efficiency, quality and environmental performance of house construction, use and demolition (Pan and Goodier, 2012). The factory precision of prefabricated housing panels has been associated with a better insulation performance, improving occupant comfort and reducing household energy demands (Steinhardt and Manley, 2016). Additionally, as seen in table 1, OSC have several benefits when compared to traditional construction methods.

Notwithstanding the increasing interest of adopting OSC methods, the UK remains behind similar economies in the uptake of offsite methodologies (Steinhardt and Manley, 2016). This growing interest is mainly driven by a shortfall in housing supply, with some reports showing that the UK needs 345,000 new homes per year (Housing, Communities and Local Government Committee, 2019) and the increasing pressure from the government for the emulation of the manufacturing sector (Parliament, 2018).

LC is a moderately new approach that focuses on minimising activities that do not generate value for the project owner. In this context, these non-value adding activities are considered wastes (Tafazzoli et al, 2020). Variety has been considered as one of the main reasons that Lean production is not suitable for the construction industry (Yu et al., 2013). However, Yu et al. (2013) also add that this variety is the ground on which the Lean production system was based and the reason that Lean production is different from mass production ineffectiveness. As seen in table 1, LC provides several benefits for the AEC industry and essentially aims to work on constant improvement, strong user focus, value for money, waste elimination, high-quality management of projects and efficient supply chain (Office of Government Commerce, 2000).

Table 1: Benefits of BIM, LC and OSC

\begin{tabular}{|c|c|c|}
\hline Benefits of BIM & Benefits of LC & Benefits of OSC \\
\hline $\begin{array}{l}\text {-Clash detection improves } \\
\text { communication; models can be } \\
\text { updated in real-time allowing the } \\
\text { exchange of critical information } \\
\text { throughout the project lifecycle } \\
\text { (Banuelos Blanco and Chen, 2014). } \\
\text {-Predesign analysis prevents time } \\
\text { consuming redesign (Azhar, 2011). } \\
\text {-Effective data management improves } \\
\text { the efficiency of activities such as } \\
\text { quantity surveying, procurement and } \\
\text { material supply integration (Steel et al., } \\
\text { 2012). }\end{array}$ & $\begin{array}{c}\text {-Waste reduction and } \\
\text { enhanced cooperative } \\
\text { relationships (Green and } \\
\text { May ,2005). } \\
\text {-Increased process } \\
\text { efficiency and labour } \\
\text { productivity (Goh and } \\
\text { Goh, 2019). } \\
\text {-Improved quality and } \\
\text { productivity through } \\
\text { effective collaboration } \\
\text { between stakeholders } \\
\text { (Bernstein and Jones, } \\
\text { 2013) }\end{array}$ & $\begin{array}{l}\text {-Effective quality control in } \\
\text { complying with quality } \\
\text { standards (Blismas et al., } \\
\text { 2006). } \\
\text {-Preliminary costs are lower, } \\
\text { less waste, less onsite damage } \\
\text { and increase of economic value } \\
\text { (Elnaas et al., 2014). } \\
\text {-Less site disruption, removal of } \\
\text { extensive operations off site, } \\
\text { work can be carried out } \\
\text { simultaneously offsite and } \\
\text { onsite (Blismas et al., 2006). } \\
\text {-Risk reduction and better } \\
\text { safety due to carefully planned } \\
\text { processes in a factory (Ajayi et } \\
\text { al., 2019). }\end{array}$ \\
\hline
\end{tabular}

\section{BIM AND OFFSITE CONSTRUCTION}

According to Azhar (2011), over the past decade, BIM has added significant value to the construction sector and, as Aranda-Mena et al. (2009) state, has proven to be more than just a modelling tool by providing relevant benefits throughout the entire construction 
lifecycle, from design to occupancy and maintenance. The UK Government's BIM Level 2 mandate helped the construction industry to become a world leader in BIM adoption (Alwan et al., 2017). This mandate requires collaborative BIM level 2 models on all government-funded projects from 2016 onwards (Government, 2013).

Offsite manufacturing can be facilitated by BIM in several ways. It helps in the specification of material requirements which results in reducing over-ordering and minimise waste in the construction site (Abanda et al, 2017). BIM also allows the accurate representation of geometry, behaviour and properties of individual components that can facilitate their incorporation into modularised building elements made available digitally (Nawari, 2012). Notwithstanding these benefits, barriers such as limited interoperability and standardisation, lack of confidence in small organisations about their BIM skills and client's unawareness of BIM benefits are still hindering the adoption of BIM in the AEC industry. However, Abanda et al (2017) argue that BIM can enhance the existing benefits of OSC and can notably contribute to overcoming the barriers that are currently hindering the uptake of OSC. Although several studies have identified the benefits of BIM on conventional construction (Table 1), it can be argued that the impact of these benefits in OSC can be greater given that OSC has numerous benefits over traditional construction.

\section{SYNERGIES BETWEEN BIM AND LEAN CONSTRUCTION FOR OFFSITE CONSTRUCTION}

Despite the latent benefits of OSC and LC, there is a lack of design assessment tools that integrate both concepts to support designers and managers in evaluating the implications of efficient assembly processes (Gbadamosi et al., 2019). On the other hand, BIM enhances the early-stage decision- making through advanced data visualisation, clash detection, material quantity take-off, and others (Mahamadu et al., 2017).

Fundamentally, LC and BIM are different processes that separately have a significant impact on improving construction processes (Robey and Issa, 2015). Although the two approaches represent potential benefits when used together (Sacks et al., 2009), the authors suggest that further improvements can be achieved to further enhance the efficiency of both methodologies as an integrated approach. Additionally, a National Research Council (2009) study in the United States recommended five opportunities for significant advancement in construction productivity. These recommended opportunities included the use of OSC, the increased implementation of BIM, improvements in processes materials, equipment and information that have a direct relationship with LC principles. These recommendations fundamentally recognise the potential of BIM, Lean and OSC in improving and ensuring the efficiency and quality of the construction industry.

\section{RESEARCH METHOD}

As this study aims to collect data about the current implementation of BIM and LC in OSHC projects in the UK, a quantitative research approach was implemented with the use of a questionnaire survey as the main data collection tool. The study commenced by reviewing the literature available about the current status of the implementation of BIM, LC and OSC. The questionnaire survey was developed considering the results from the literature review and consists of two sections; the first section was designed to obtain relevant background information about the respondents such as occupation, years of experience and previous knowledge in BIM, LC and OSHC while the second section focuses on obtaining information regarding the practices and techniques of BIM, LC and OSC currently being implemented in the UK construction sector. 
The questionnaire survey was hosted online from August to November 2020, using Google forms. Purposive sampling was used in selecting the research participants in order to ensure that only those with adequate knowledge of the subject participated in the study. The population of the study consisted of experienced OSC professionals with background and knowledge in BIM and LC in the UK. Considering the database of the UK Offsite Hub and Building and Design, the population of OSC practitioners in the UK is estimated to be approximately 228 organizations. With a confidence level of $90 \%$ and a margin of error of $8 \%$, the ideal population sample was calculated to be seventy-three. Based on this, eighty survey links were sent out through email and social media platforms such as LinkedIn and Twitter across the four nations of the UK. However, after three months with several follow-up emails and reminders only 32 responses were received representing $44 \%$ of the ideal sample size. Although the number of responses obtained represents a valuable evidence, it should be recognized that this representative sample is fairly weak due to the low rate of responses received. Besides, the authors observed that the COVID-19 pandemic of 2020 partly impacted the number of responses received as people were unsettled to participate in the study. The data collected from the survey were analyzed using Microsoft Excel to obtain the graphics and tables.

\section{RESULTS AND DISCUSSION}

\section{RESPONDENTS BACKGROUND INFORMATION}

Most respondents are involved actively in the construction industry and have relevant roles in their organisations. Out of the 32 respondents of the survey, $25 \%$ identified themselves as Founder and CEO's of their organisation, which is the highest percentage of responses for the roles identified in the survey. The rest of the participants included construction managers, architects, project managers, quantity surveyors, engineers and offsite and LC consultants and lecturers.

\section{IMPLEMENTATION OF BIM AND LEAN CONSTRUCTION IN OFFSITE HOUSING CONSTRUCTION IN THE UK}

As this study aims to identify the status of the implementation of LC and BIM in OSHC, it was necessary to identify which methodologies have been or are currently being implemented by respondents in construction projects. As shown in figure 1, 40.63\% of participants indicated to have implemented or are currently implementing BIM- LC and OSC methods in construction projects. According to the results, BIM is the preferred methodology in construction projects by $15.63 \%$ of respondents, while LC accounts for $12.50 \%$.

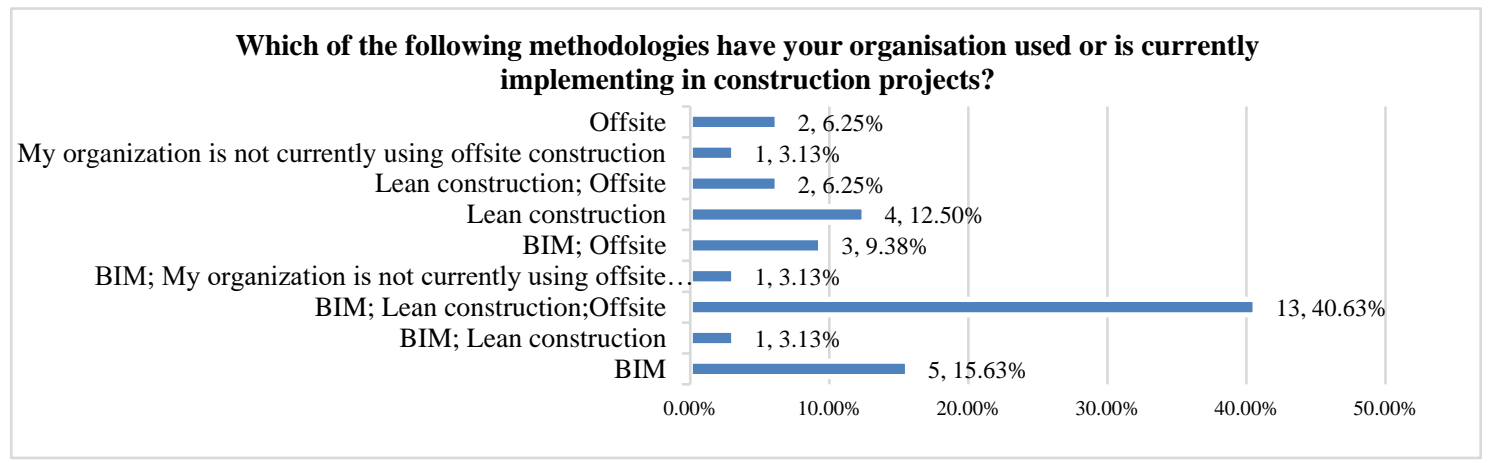

Figure 1-Methodologies implemented in offsite construction projects. 
$6.25 \%$ of respondents indicated that OSC is the only methodology being implemented their organisations. A further $9.38 \%$ of respondents indicated BIM and OSC as the main methods being implemented in construction projects while $6.25 \%$ identified LC and OSC as the methodologies of choice. These results suggest that an increasing number of organisations are currently implementing BIM and LC concepts into OSHC methods. However, the results also indicate that LC and BIM in construction projects are individually being implemented by $28.13 \%$ of respondents. In OSHC projects, $(9.38 \%)$ indicated they are currently implementing only BIM while LC implementation accounts for $6.25 \%$.

Analysing the results from the implementation of LC in OSC, $46.88 \%$ of respondents indicated to have been implementing LC in OSC projects from 1 to 5 years whereas those implementing LC in OSC for 5 to 10 years accounted for $21.88 \%$. While $9.38 \%$. stated to have been using LC in OSC from 10 to 15 years, $18.75 \%$ of respondents stated they have been implementing LC in OSC for longer than 15 years. A further $21.88 \%$ of participants indicated to have not implemented LC in OSC projects. These results correspond with the literature about an increasing LC implementation in OSC due to the benefits these two approaches can bring into construction projects (Gbadamosi et al, 2019). The increasing use of offsite in the UK in housing delivery could be due to the renewed government effort to close the housing shortage gap using OSC methods as recommended by the House of Commons housing committee (Housing, Communities and Local Government Committee, 2019).

As for the implementation of BIM in offsite, most respondents indicated they have been implementing BIM in offsite for $1-5$ years $(59.38 \%)$, followed by $25 \%$ of respondents who stated they have not implemented BIM in offsite. Also, $6.5 \%$ of respondents indicated to have been implementing BIM in offsite for 5-10 years and 1015 years respectively.

According to the previous results, despite the lack of implementation of BIM in OSC projects, there is an increasing tendency in the implementation of BIM in OSC projects in the last few years which match with the literature about the impact of government regulations and acknowledgement of the benefits of BIM for construction projects (Alwan et al., 2017). As shown in figure 2, the most used OSC method being implemented is the Modular system with $62.50 \%$ of participants, whereas Volumetric is the second most implemented OSC method with $56.25 \%$. These results match with the literature where the Modular system is highlighted as one of the most implemented OSC techniques in residential and hospitality buildings (Lawson et al, 2012) whilst Volumetric implementation has been increasing amongst UK housebuilders due to its several benefits in helping to tackle the ageing workforce and labour shortages (Booth, 2017).

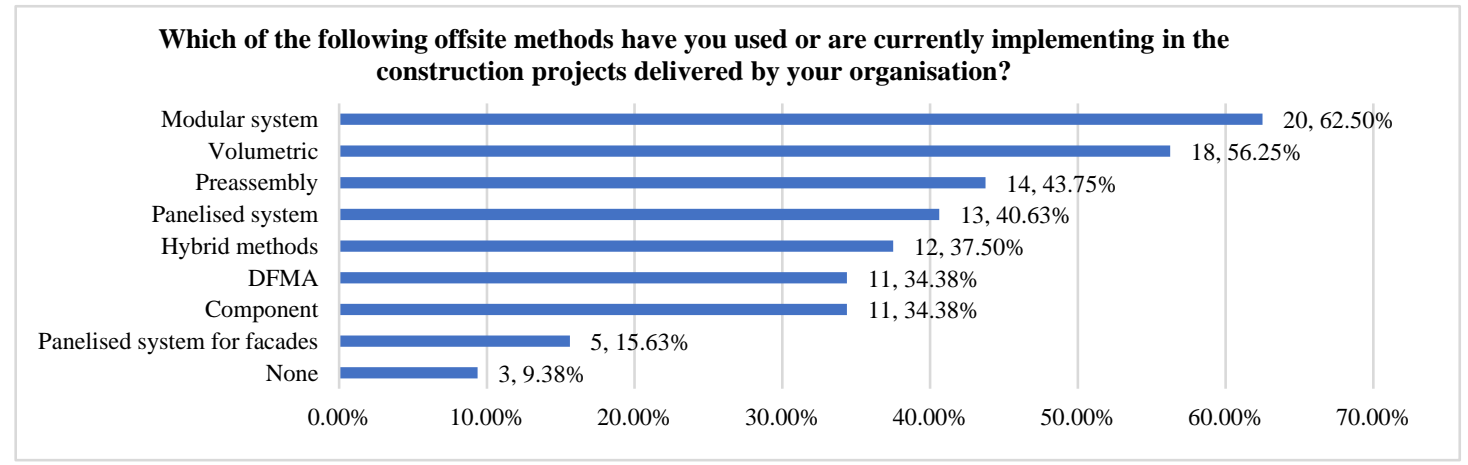

Figure 2-Offsite methods used in the delivery of construction projects. 
As can be identified in figure 3 , the questionnaire survey highlights the Lean concepts being implemented in offsite projects by participants. Just In Time (JIT) was chosen as the main Lean technique implemented in projects with $56.25 \%$ of participants. Followed by Visual Management (34.38\%) and Last Planner (34.38\%), Target Value Design (28.13\%) and Value Stream Mapping (28.13\%), 5S (25.00\%) and Lean Project Delivery System (25.00\%),. Process mapping (18.75\%), First Run Study (15.63\%), Mistake Proofing (15.63\%) and Takt Time Planning (15.63\%). 12.50\% of participants indicated not having implementing any of these LC concepts while only $6.25 \%$ of participants chose Choosing by advantages as one of the techniques applied in their projects. These results clearly show that construction companies in the UK have embraced the philosophy of JIT, due to its numerous benefits in construction projects such as increased productivity and quality (Pheng and Shang, 2011).

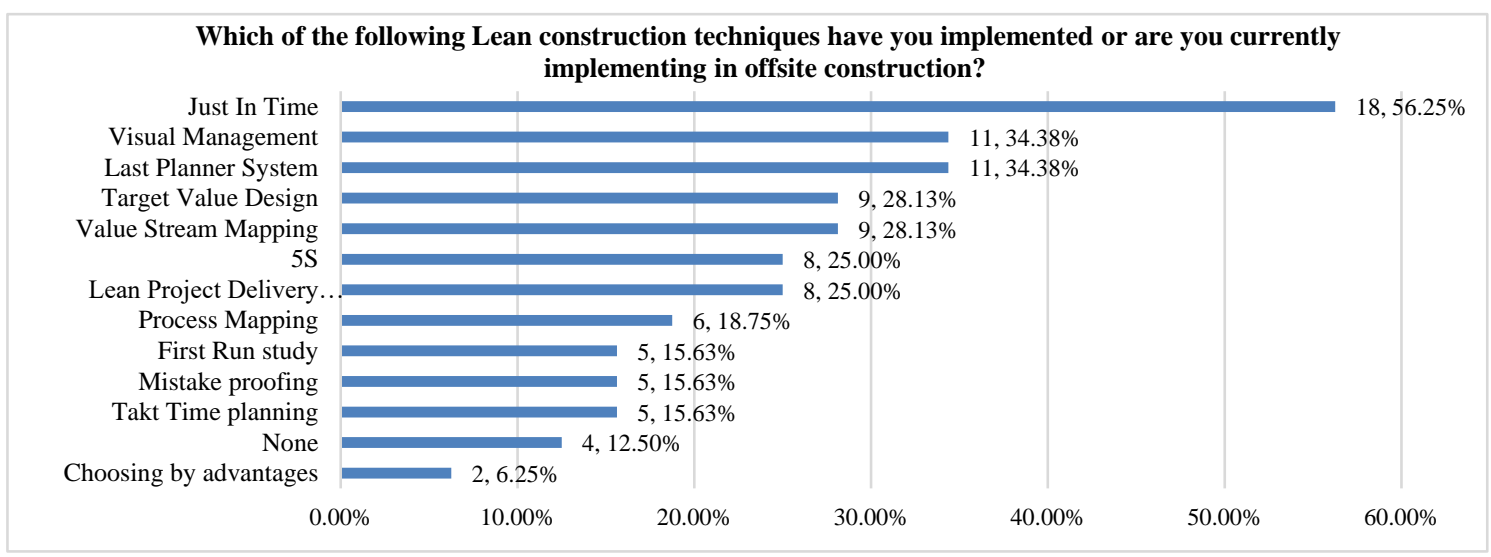

Figure 3-Lean techniques used in offsite projects.

\section{INTEGRATION OF BUILDING INFORMATION MODELLING AND LEAN CONSTRUCTION FOR OFFSITE HOUSING CONSTRUCTION}

The integration of BIM and LC for Offsite projects was assessed by showing participants several benefits of offsite construction processes and asking them to identify the likelihood of these benefits to be achieved by the combination of these two approaches. As shown in figure 4, respondents considered that effective collaboration would be the main benefit of integrating LC and BIM with a weighted average of 4.6. Because the production process of off-site construction is fragmented, and OSC projects should involve close cooperation of multiple interdependent stakeholders, better quality control is a major challenge to promote OSC projects (Pablo and London, 2020). LC tools such as Kanban and huddle meetings can provide a new platform to increase value to BIM and improve construction site collaboration (Von Heyl and Demir, 2019).

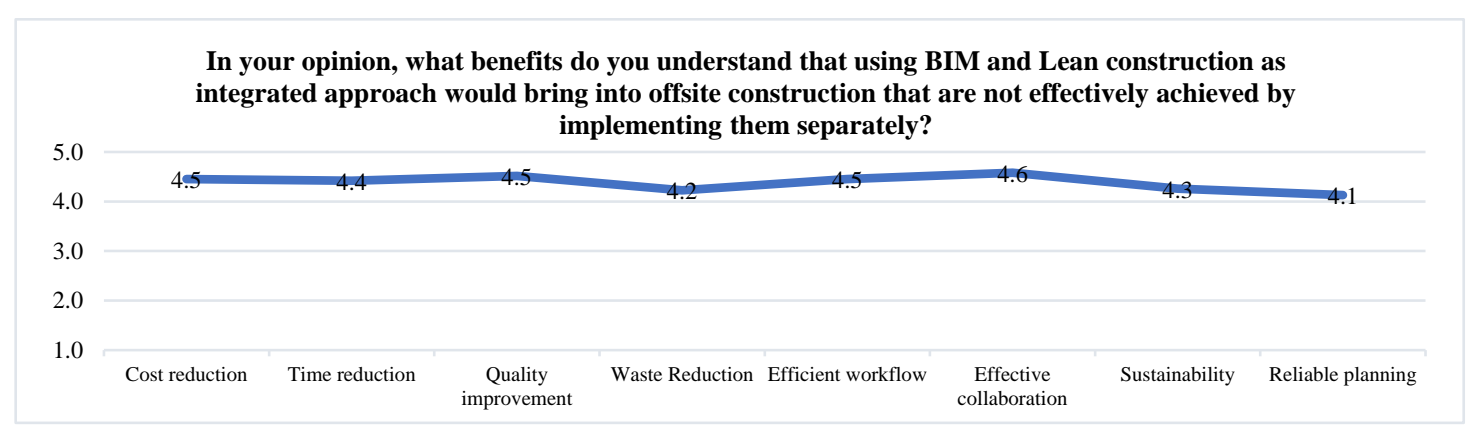

Figure 4-Benefits of integrated BIM-Lean for offsite projects. 
Similarly, participants agreed that cost reduction, efficient workflow and quality improvement are three main benefits of integrating these two approaches for offsite with both obtaining a weighted average of 4.5. That is because BIM provides a digital platform through which participants can effectively share and manage information of the project, while LC practices solve the problem of enhancing the coordination of the stakeholders, and smooth the workflow by reducing waste and adding value (Zhang et al., 2018).

\section{CONCLUSIONS AND FUTURE RESEARCH}

This study was undertaken to evaluate the current practices and status of the implementation of BIM and LC in OSHC projects in the UK. The investigation reveals that the implementation of LC in OSC has been increasing considerably over the last 5 years, with techniques such as JIT, Visual management and Last Planner System amongst the most implemented in offsite projects particularly. The study established the most used offsite methods in the UK include modular, volumetric and preassembly. Similarly, the study shows that the use of BIM in the delivery of OSHC projects in the UK has seen an increase in the last five years. In term of the benefits of the implementation of LC and BIM in OSHC projects, this study revealed that these two methodologies when appropriately implemented can bring several benefits such as efficient collaboration and team integration, time reduction, cost reduction, quality improvements, efficient workflow, waste reduction and sustainability, customer's satisfaction, higher performance and risk reduction.

This study contributes to the current knowledge and future implementation of BIM and LC in OSHC projects. The evidence presented would enable project practitioners to understand the importance of the integration of BIM and LC in the delivery of OSHC project. Although the response is low due to COVID-19, this study shed light on the current status of implementation of BIM and LC in OSHC and the benefits of the implementation of both BIM and LC in OSHC processes in the UK. Additionally, the results of this study would enable further improvements on the implementation and synergies between these methodologies to effectively increase efficiency and quality in the AEC industry in the UK.

\section{REFERENCES}

Abanda, F. H., Tah, J. H. M., \& Cheung, F. K. T. (2017). "BIM in off-site manufacturing for buildings." J. Build. Eng., 14, 89-102.

Ajayi, S. O, Oyedele, L. O., Akinade, O. O, Bilal, M, Owolabi, H. A., Alaka, H. A., and Kadiri, K. O. (2016) "Reducing waste to landfill: A need for cultural change in the UK construction industry." J. Build. Eng., 5, 185-193.

Alwan, Z., Jones, P., and Holgate, P. (2017). "Strategic sustainable development in the UK construction industry, through the framework for strategic sustainable development, using BIM." J. Clean. Prod., 140, 349-358.

Aranda-Mena, G., Crawford, J., Chevez, A., and Froese, T. (2009). "Building information modelling demystified: does it make business sense to adopt BIM?" Int. J. Manag. Proj. Bus., 2(3), 419-434.

Azhar, S. (2011). "Building Information Modelling (BIM): Trends, benefits, risks, and challenges for the AEC industry." Leadersh. Manag. Eng., 11(3), 241-252.

Banuelos Blanco, F.G. and Chen, H. (2014), "The implementation of building information modelling in the UK by the transport industry." Procedia Soc Behav Sci., 138, $510-520$. 
Bernstein, H.M. and Jones, S.A. (2013). Lean construction: Leveraging collaboration and advanced practices to increase project efficiency. McGraw Hill Construction, Bedford, MA.

Bhatla, A., \& Leite, F. (2012). "Integration framework of BIM with the last planner system." In IGLC 2012 - 20th Conf. Int. Gr. Lean Constr.

Blismas, N., Pasquire, C. and Gibb, A. (2006). "Benefit evaluation for off-site production in construction." Constr. Manag. Econ., 24(2),121-130.

Booth, R. (2017) "UK housebuilders to prefabricate hundreds of homes in factories." https://www.theguardian.com/business/2017/dec/31/uk-housebuilders-factoriesprefabricating-homes (Sep.15, 2020).

Eastman, C., Teicholz, P., Sacks, R., and Liston, K. (2008). "BIM for the Construction Industry." In BIM Handbook (pp. 207-242).

Egan, J. (1998). Rethinking Construction. DETR, London.

Elnaas H., Gigado K. and Ashton P. (2014). "Factors and drivers effecting the decision of using off-site manufacturing (OSM) systems in house building industry." J. Oper. Prod. Manag., 4(1), 51-58.

Farmer, M., (2016). "The farmer review of the UK construction labour model." Construction Leadership Council.

Gbadamosi, A. Q., Mahamadu, A. M., Oyedele, L. O., Akinade, O. O., Manu, P., Mahdjoubi, L., \& Aigbavboa, C. (2019). "Offsite construction: Developing a BIMBased optimizer for assembly." J. Clean. Prod., 215, 1180-1190.

Goh, M. and Goh, Y. M. (2019). "Lean production theory-based simulation of modular construction processes." Aut. in Const. 101, 227-244.

Green, S. and May, S. (2005). "Lean construction: arenas of enactment, models of diffusion, and the meaning 'leanness." Build. Res. Inf., 33(6), 498-511.

Housing, Communities and Local Government Committee (2019). "Modern methods of construction."

Available at:https://publications.parliament.uk/pa/cm201719/cmselect/cmcomloc/1831/1831.p df (Dec. 22,2019).

Kolo, S. J., Rahimian, F. P., \& Goulding, J. S. (2014). "Offsite manufacturing construction: A big opportunity for housing delivery in Nigeria." Procedia Eng., 85, 319-327.

Lawson, R. M., Ogden, R. G., \& Bergin, R. (2012). "Application of Modular Construction in High-Rise Buildings. ” J. Archit. Eng., 18(2), 148-154.

Machado, M., Underwood, J., \& Fleming, A. (2017). "Implementing BIM to Streamline a Design, Manufacture, and Fitting Workflow.” Int. J. 3-D Inf. Model., 5(3), 31-46.

Mahamadu, A. M., Mahdjoubi, L., \& Booth, C. A. (2017). "Critical BIM qualification criteria for construction pre-qualification and selection." Archit. Eng. Des. Manag., 13(5), 326-343.

Manufactured Housing Research Alliance (2007). "Pilot Study: Applying Lean Principles to Factory Home Building. Technical Report." U.S. Department of Housing and Urban Development.

Nanyam, V. P. S. N., Sawhney, A., \& Gupta, P. A. (2017). "Evaluating Offsite Technologies for Affordable Housing." Procedia Eng., 196, 135-143.

Office of Government Commerce (2000). "Achieving Sustainability in Construction Procurement, by the Sustainability Action Group of the Government Construction Clients." Panel (GCCP), available at: 
www.ogc.gov.uk/documents/Sustainability_in_Construction_Procurement.pdf (Jul. 18, 2020).

Oskouie, P., Gerber, D. J., Alves, T., \& Becerik-Gerber, B. (2012). "Extending the interaction of BIM and lean construction." In IGLC 2012 - 20th Conf. Int. Gr. Lean Constr., 1, (617), 111-120.

Pablo, Z., \& London, K. A. (2020). "Stable relationality and dynamic innovation: two models of collaboration in SME-driven offsite manufacturing supply chains in housing construction." Eng. Constr. Archit. Manag., 27(7),1553-1577.

Pan, W., \& Goodier, C. (2012). "House-Building Business Models and Off-Site Construction Take-Up." J. Archit. Eng., 18(2), 84-93.

Pasquire, C., Gibb, A., \& Blismas, N. (2004). "Off-site Production: Evaluating the Drivers and Constraints." 12th Annu. Conf. Int. Gr. Lean Constr., 655-662.

Pheng, L. S., \& Shang, G. (2011). "The application of the Just-in-Time philosophy in the Chinese construction industry." J. Constr. Dev. Ctries., 16(1), 91-111.

Robey, M. W., \& Issa, R. R. A. (2015). "Implementation of Prefabrication and Modular Offsite Construction using BIM and Lean Construction Techniques." In Modul. Offsite Constr. Summit Proceedings.

Sacks, R., Dave, B. A., Koskela, L., \& Owen, R. (2009). "Analysis framework for the interaction between lean construction and Building Information Modelling." In Proc. IGLC17 17th Annu. Conf. Int. Gr. Lean Constr.

Smith, D.K. and Tardif, M., (2009). Building information modelling: a strategic implementation guide for architects, engineers, constructors, and real estate asset managers. John Wiley \& Sons. Hoboken, NJ.

Steel, J., Drogemuller, R. and Toth, B. (2012), "Model interoperability in building information modelling." Softw. Sys.t Model., 11(1), 99-109.

Steinhardt, Dale. A. and Manley, K. (2016) "Adoption of prefabricated housing-the role of country context." Sustain. Cities Soc., 22,126-135.

Tafazzoli, M., Mousavi, E., \& Kermanshachi, S. (2020). "Opportunities and challenges of green-lean: An integrated system for sustainable construction." Sustain. (Switzerland)., 12(11), 44-60.

UK parliament (2018) "Off-site manufacture for construction: Building for change" 2nd Report of Session 2017-19 - published 19 July 2018 - HL Paper 169.

Von Heyl, J. \& Demir, S. (2019). "Digitizing Lean Construction With Building Information Modelling." In:, Proc. 27th Conf. Int. Gr. Lean Constr., 843-852.

Zhang, X., Azhar, S., Nadeem, A., \& Khalfan, M. (2018). "Using Building Information Modelling to achieve Lean principles by improving efficiency of work teams." Int. J. Constr. Manag., 18(4), 293-300. 